\title{
Gendered, Non-Gendered, Re-Gendered Tools for Spatial Production
}

\section{Gem Barton \& Harriet Harriss}

To cite this article: Gem Barton \& Harriet Harriss (2017) Gendered, Non-Gendered, Re-Gendered Tools for Spatial Production, Architecture and Culture, 5:3, 475-485, DOI: 10.1080/20507828.2017.1383796

To link to this article: $\mathrm{http}: / / d x . d o i . o r g / 10.1080 / 20507828.2017 .1383796$

\section{Published online: 27 Oct 2017.}

Submit your article to this journal 저

View related articles

View Crossmark data $₫$ 


\section{ARCHITECTURE AND CULTURE}

\author{
Gem Barton \\ Architecture, University of \\ Brighton, UK \\ G.Barton@brighton.ac.uk \\ Harriet Harriss \\ Architecture, Royal College \\ of Art, School of Fine Art, \\ London, UK \\ harriet.harriss@rca.ac.uk
}

(A) Check for updates
Volume 5/Issue 3

November 2017 pp 475-485

DOI: $10.1080 / 20507828$.

2017.1383796

No potential conflict of interest was reported by the authors.

(c) 2017 Informa UK Limited, trading as Taylor \& Francis Group

\section{Gendered, Non-Gendered, Re-Gendered Tools for Spatial Production Gem Barton and Harriet Harriss}

\section{Introduction}

\begin{abstract}
We constantly drift between the object \& its demystification, powerless to render its wholeness. For if we penetrate the object, we liberate it but we destroy it; and if we acknowledge its full weight, we respect it, but we restore it to a state which is still mystified. ${ }^{1}$
\end{abstract}

I haven't perceived a texture until I've instantaneously hypothesised whether the object l'm perceiving was sedimented, extruded, laminated, granulated, polished, distressed, felted or fluffed up. ${ }^{2}$

The perennial question, "Can design be genderless?" is further complicated by our contingent, nuanced and transient gender identities. Our collective focus is more often upon whether spatial outcomes are gendered, rather than the gender of the processes themselves. In contrast, this paper considers to what extent our making processes are gendered and the role of linguistics in assigning gender to the tools of production. It also asks whether tools can be un-gendered, re-gendered or non-gendered, and reflects upon the need for a collective, critical awareness of the influence of gendered tools over our design processes and outcomes. It asserts the need for spatial producers - of all genders - to use un-gendered, re-gendered 
or non-gendered tools in order to subvert and disrupt making and maker stereotypes, and as a means critically to assess their practical utility and political influence.

Writing from the perspective of interior design and architecture educators familiar with the parallels between object versus absence-ofan-object and exteriority versus interiority disciplinary tensions, this paper explores the extent to which we are complicit agents of gender assignation: by failing to question both the tactic and explicit identity of the objects or tools used to author space. We do this by examining the role of linguistics in assigning gender to objects, calling into question the extent to which (1) gendered objects inform the wider social relations of space; and (2) whether un-gendered, re-gendered or non-gendered tools of spatial production are needed, and what these might look like. Our analysis draws from two key sources: the work of selected artists addressing the gender of objects and the primary data outcomes generated within a gendered tool-making exercise at the AHRA Architecture and Feminisms Conference (at KTH, Stockholm, November 2016). In the second example, participants were invited to engage in making their own un-gendered, non-gendered and re-gendered tools for spatial production using what is now commonly understood as "hacking" methodologies. A typical "hack" involves several days intensive, multidisciplinary teamwork, where the problem is taken apart as a means to find the solution. Often competitive, sweaty and messy, hacks are used to work out solutions to any kind of product, service or space challenge, and can involve looping back on problems, or deconstructing and reconstructing existing objects or ideas to find new applications and meaning. To run the workshop as a design "hack" was intended to disrupt the linearity of making and to allow for reinvention as much as invention. This tactic aligns with what anthropologist Daniel Miller identified as the ability of objects "continually [to] assert their presence as simultaneously material force and symbol. They frame the way we act in the world, as well as the way we think about the world."3 Subsequently, the tools produced in the workshop are qualitatively examined using the theoretical tools of constructivism within a feminist analytical framework.

\section{Tools gendered grammar and linguistic relativity}

Feminist language critique has identified that gendered language disadvantages women, and also affects the way in which everyone interprets the world around them. ${ }^{4}$ In many European languages, objects (nouns) without a biological sex are assigned a grammatical gender that arguably influences how we cognitively perceive and use them (linguistic relativity). The English word "the," for instance, has three equivalents in German: der (masculine), die (feminine), das (neuter). These assignations enable the categorization of inanimate and abstract nouns by gender association. For example, a simple door key is masculine in German and yet feminine in Spanish. And as one study focused upon this distinction identifies, German speakers were inclined to describe the key as "hard, heavy, jagged, metal, and useful," whereas Spanish-speaking participants
476

Gendered, Non-Gendered, Re-Gendered Tools for Spatial Production

Gem Barton and Harriet Harriss 
preferred to describe the same key as "golden, intricate, little, lovely, and tiny." In contrast, the word "bridge" is feminine in German and masculine in Spanish. Within the same study, German speakers described bridges as "beautiful, elegant, fragile, pretty, and slender," whereas Spanish speakers preferred "big, dangerous, strong, sturdy, and towering." Of course, not all languages contain explicit gender assignations. Only one-quarter of the world's languages use gendered noun classifications. Indeed, languages as regionally diverse as Indonesian and Finnish have no grammatical genders whatsoever, therefore we are mindful of the inherent biases in writing from a Western perspective. Across most of Europe, however, languages can be divided into three gender-related groups: grammatical gender languages, natural gender languages and genderless languages. ${ }^{6}$ In the English language (natural gender) there are no such grammatical gender assignations. However, the etymology of many English words have Latin (Spanish), Germanic or French origins, so the gender assignations are more tacit, only surfacing occasionally, when certain objects are given feminine, third-person pronouns - such as ships, cars or the most obvious "mother" nature - most usually to assert authority over the object or bring it under control. Perhaps an exaggerated example of this can be found within Hawaiian linguistics, where there are two genders known as kino ' $\bar{o}$ (o class) and kino ' $\bar{o}$ (a class). Kino ' $\bar{o}$ nouns refer to "spaces" or anything you can enter, anything you can put on and anything you have no control over. Kino ' $\bar{o}$ nouns refer to everything you do have control over: your actions, extending to the people you "choose" to live life with. Subsequently, the gender of the language used to describe space and space-making also becomes a question of ownership, authority and control. The question of ownership extends to human beings - which are almost always assigned to the masculine gender, whereas women are often denied belonging to the feminine gender. In German, for example, das Mädchen ("the girl") and das Fräulein ("unmarried woman") are neutral (or "neuter" to use the correct linguistic term), implying their lack of autonomy from men and masculinity. This becomes particularly problematic in relation to inanimate objects. For example, in French a man's beard is feminine (la barbe) - implying the status of women as a form of adornment - and prompting the founding of feminist activist group of the same name. ${ }^{8}$ Interestingly, whilst water is feminine in Russian, if you dip a teabag inside "her," she becomes masculine, highlighting the significance of the "void" in relation to gender.

\section{Gendered objects for spatial production}

The sense in which the discipline of architecture stands back from the object, and simultaneously desires the object guarantees the anxiety associated with the admission of women into its ranks. ${ }^{9}$

An example of the ownership of the means of space-making can be found in the gender assignation of the objects or tools of architectural production. For example, a drawing board (a zeichenbrett in German or a tablero de 


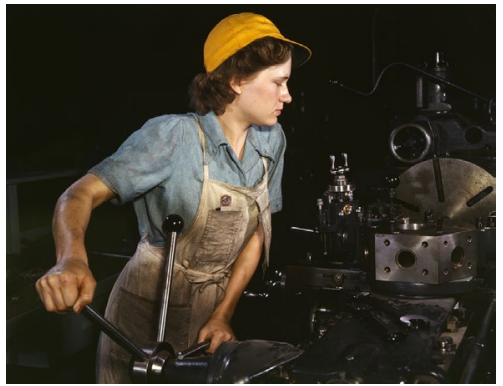

Figure 1(a)

"Rosie the riveter," 1940s. A turret lathe operator machining parts for transport planes at the Consolidated Aircraft Corporation plant, Fort Worth, Texas, USA. Source: US Library of Congress, Prints and Photographs Division, digital ID fsac.1a34951; Wikimedia.

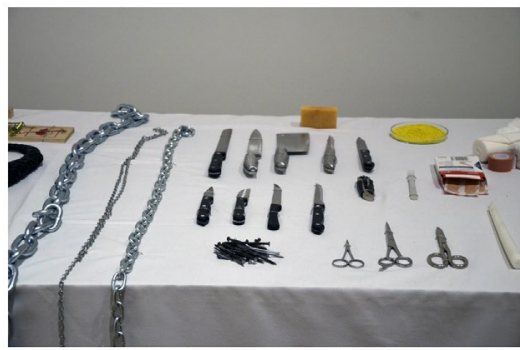

Figure 2(a)

Maria Abramović, Rhythm “0”, 1974. Source: Flickr - Marc Wathieu.

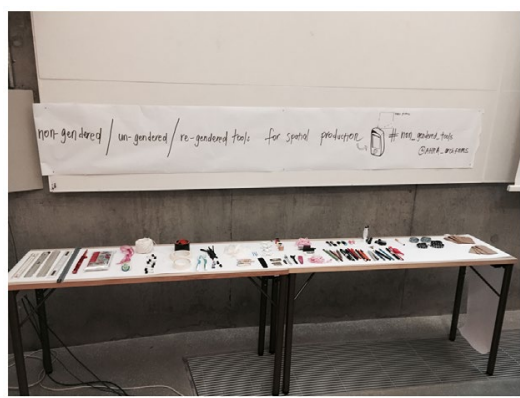

Figure 3(a)

Tableau of Objects from "Non-gendered/ un-gendered/re-gendered tools for spatial production" artifacts workshop, AHRA conference, Stockholm, Sweden. Source: Authors.

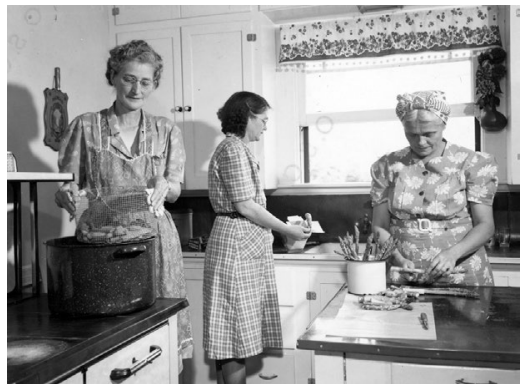

\section{8}

Gendered, Non-Gendered, Re-Gendered Tools for Spatial Production

Gem Barton and Harriet Harriss
Figure 1(b)

"Woman riveted by cooking," 1940s. Source: OSU Special Collections and Archives; Wikimedia.

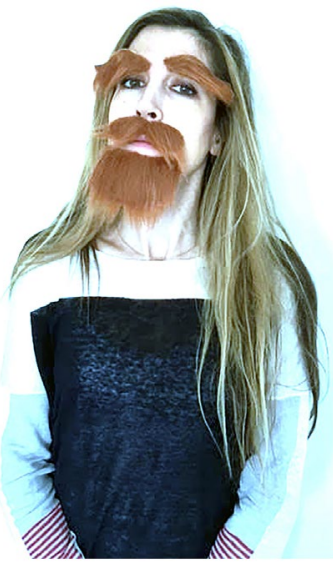

Figure 2(b)

Example of Le Barbe activism. Source: Authors.

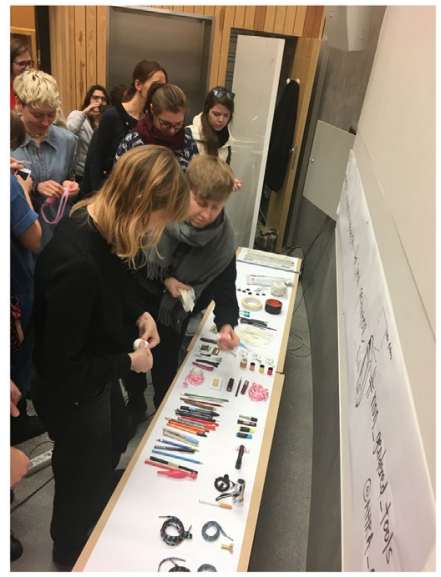

Figure 3(b)

AHRA conference delegates engaging with the Tableau of Objects (Figure 3(a)). Source: Authors. 


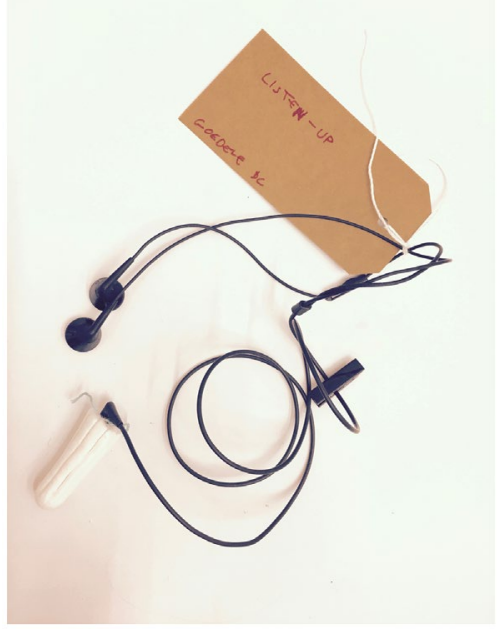

Figure 4(a)

"listen-up" (tampon headphones). Source: Authors. Photograph taken during the AHRA conference. Tool named by its creator.

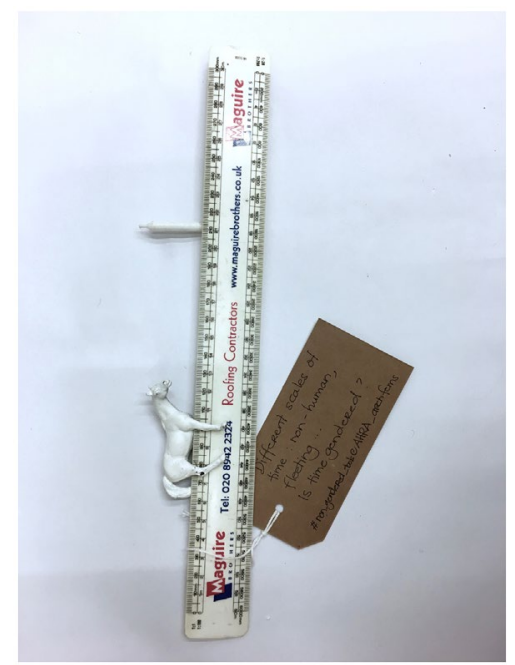

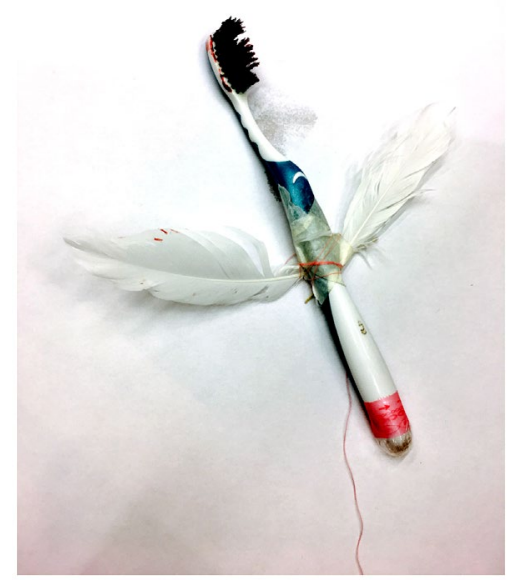

\section{Figure 4(b)}

"angelic blood-red, toothbrush totem." Source: Authors. Photograph taken during the AHRA conference. Tool named by its creator.

\section{Figure 4(c)}

"different scales of time: non-human, fleeting is time gendered?" Source: Authors. Photograph taken during the AHRA conference. Tool named by its creator.

dibujo in Spanish) a pen (a stylo in French, a stift in German or an estilógrafo in Spanish) and paper (papier in French, papel in Spanish) are male nouns. Even the world "building" (bâtiment, gebäude, edificio) is masculine in all three languages. In returning to Boroditsky's linguistic study, it becomes clear that the male-gender specificity of the tools used to architect space trigger cognitive preconditions that influence how we engage with spatial 
production. If there is a gender bias in the processes, then surely this is transposed into the outcomes, too, which may also affect who gets to design and whom we find ourselves designing for. Jennifer Prewitt-Freilino's research into the influence of gendered linguistics upon social and spatial hierarchies considers the correlation between linguistic gender assignation and gender inequality by country. If societal structures are influenced by gendered linguistics, it seems reasonable to assume that the gendered tools of spatial production are similarly affected..$^{10}$ Perhaps this might account for the maleness of the architectural profession, given the low proportion of female architects who report high levels of sexism (not to mention racism and homophobia) within the industry. ${ }^{11}$

Regardless of gender, the risk remains that our choice of gendered tools for spatial production may tacitly or even explicitly transpose gendered values into our spatial outcomes, not least because the relationship between the tools of design and creation, and the product/ output itself, is both physical and metaphysical in manifestation. What this means is that spaces that were previously considered the territory of women - for example, the home - are potentially still controlled by masculine values inherent in the processes of spatial production. This calls into question the degree to which these spaces are "feminine" and may begin to explain why women are seemingly still under domestic control even within the spaces of which they are traditionally afforded ownership.

Having previously been denied access to the workplace, early twentieth-century women were expected to focus upon becoming skilful and creative "home-makers" by displaying culinary to craft expertise often requiring a range of complex tools. When World War II labor shortages required women to enter the workplace, they were unsurprisingly agile in adapting to skilled industrial tasks previously considered beyond them: home-making had perhaps provided them with forms of expertise applicable in industry. Indeed, innovations in post-war domestic appliances were no doubt driven by a need to persuade women to give up their jobs and return to the home, to enable the returning soldiers to re-claim their former jobs. It evidently was not enough simply to make them pink. ${ }^{12}$ Subsequently, the extent to which women have influenced tools for spatial production and, in general, tools we would otherwise associate with the professional activities of men - might be far greater than we previously assumed.

\section{The Stockholm workshop: prose positioning piece}

In her The Third Body (2010), Hélène Cixous uses fantasy, anecdote and lyricism, amongst other things, to evoke the narrators' relationship with her lover as one that alternates between presences, absences, separations and reconnections. Drawing inspiration from this approach, one of the authors of this paper composed a segment of prose highlighting the relationship between tools and creation, and as such, women and their constructed environments. The prose below was read aloud to the workshop participants during the tool making/re-making workshop in Stockholm as a means to assert cognitively the philosophical inquiry underpinning the exercise:
480

Gendered, Non-Gendered, Re-Gendered Tools for Spatial Production Gem Barton and Harriet Harriss 
To make, to create, to build, ... to CRAFT.

Craft with utensils, with tools, with kits ... with TRAPPINGS.

Trappings of might, of valour, of courage ... of HEROISM.

Heroism of courage, of freedom, of neutrality ... of OBJECTIVITY.

Objectivity of space, of place, of house, ... of HOME.

A home, a room, a status, ... a SYMBOL.

A symbol of struggle, of bias, of favouritism, ... of PREFERENCE.

A preference of ease, of comfort, of tradition, ... of CONSTRUCT.

A construct, a theory, a paradigm, ... a LIFE.

A life of objects, of belongings, of entities, ... of LABELS.

Labels of gender, of age, of ability, ... of SEXUALITY.

Sexuality of feeling, of memory, of emotion ... of SENTIMENT.

Sentiment of love, of hate ... of INDIFFERENCE.

Indifference of association, of class, of kind ... of RELATIONS.

Relations of meaning, of insight, of intent ... of AMBITION.

Ambition of change, of trade, of modification ... of REVOLUTION. (Gem Barton, 2016)

The role of fantasy that Maria Abramović and Cixous embody is key to liberating oneself from the dictates of binary gender identity, evoking the freedom to infer, to speculate ... to create and the ability to imagine a new world, re-imagine the existing one. As Cixous once said, "I give myself a poet's right, otherwise I would not dare to speak." ${ }^{33}$ Similarly, by using prose to distinguish the academic presentation of the inquiry from the creative request, the intention was to offer participants a poetic entitlement to make and re-make a new relationship with the tools of spatial production. By configuring new objects from old, the tools of spatial production are divorced from their linguistic ties, hacked from their social connotations, and primed for new forms of spatial imaginings.

\section{The Stockholm workshop: from objects to tools}

What we need to question is bricks, concrete, glass, our table manners, our utensils, our tools, the way we spend our time, our rhythms. ${ }^{14}$

In 1974, Maria Abramović stood motionless in an art gallery next to a table containing objects associated with pain or pleasure: a whip, honey, grapes, a feather, knives, lipstick, a camera, a scalpel, a rose, and a gun and a single bullet, and endured multiple assaults from gallery attendees. Invariably, these tools were used to cut, harm and humiliate Abramović by the audience, and even involved a mortal threat, requiring intervention (Figure 2(a)). Much like Abramović's tableau, our AHRA workshop in Stockholm offered a tableau of objects that the audience was invited to re-gender/non-gender/un-gender (Figures 3(a-b)): tools that could - 
unlike Abramović's installation - cause harm as well as good. Whereas some of the items were traditional tools for spatial production, such as rulers, pens, compasses, others could be considered explicitly female artifacts, such as tampons and lipstick, and crucially (and even ironically) not associated with creativity or acts of production. We also provided children's toys and everyday domestic unisex items such as toothbrushes for the participants to engage with, and like Abramovićs tableau, we included items associated with erotic pleasure such as feathers, ties and tape. Due to time constraints, the focus of the workshop was limited to the creation of the tools, rather than their creative (or corporeal) application. However, the workshop highlighted the way in which Abramović's Rhythm "O" embodied "hack" methodologies long before both the term and process were claimed by today's designers. Object utility and identity was subverted through the mediating effect of a female body, in much the same way that architecture's utility and identity is either established or challenged by the often overlooked needs of female end users. Whether an intentionally female-gendered tool used as tools to design architecture might change architecture clearly requires further testing and application. However, even speculating upon how a feathery and bristly hand tool might shift spatial construction inspires thoughts of blurred material boundaries, and toddlersafe, soft edges that caress and stroke upon contact. Consequently, we recognize that our study makes limited utility of Abramović's legacy, but her methodologies - as potential architectural processes - are, in our view, wholly useful.

If, "the design processes of architecture and interior design share the same procedural sequence and core discipline vocabulary," 15 then could non-procedural or specifically non-gendered, un-gendered or re-gendered tools result in liberated forms of design vocabulary? By asking this question of participants attending the AHRA Architecture and Feminisms Conference, in Stockholm, ${ }^{16}$ we were able to observe not only the tools participants created but also the language used to define them.

\section{Gender-hacking artifacts}

If objects "arouse curiosity, resist implausible manipulation, and collect layers of information about them,"17 applying any one interpretation to the objects generated during the workshops would prove both problematic and pointless. What the forms and the names assigned to the objects did reveal, however, was an inclination towards using them as a means (1) to subvert stereotypes and (2) to critique (Figures $4(\mathrm{a}-\mathrm{c})$ ).

Whilst feminist constructivist analysis emphasizes the way in which meaning is socially constructed, it also reminds us that knowledge is situated within specific discourses, contexts, regions and other forms of constructed identity beyond gender. For this reason, we make no attempt to suggest that these artifacts provide a solution to the problem of gendered tools for spatial production - and, perhaps more poignantly, who gets to author both the tools themselves and the spaces they are used to configure. Instead, we argue that if gender is a socially constructed category, then it
Gendered, Non-Gendered, Re-Gendered Tools for Spatial Production Gem Barton and Harriet Harriss 
can and should be made and remade - and that this making and remaking needs to involve all gender categories and involve processes and not just outcomes.

\section{Conclusions}

Instead of speaking of "women" we should speak of the unstable and shifting equations produced by the conjunction of architecture + female + male + architecture, or word + object + architecture; and we would have to specify which part of architecture we meant ... this would be the project that would discover what the ambiguity of outside/inside and invention might mean for women in architecture. ${ }^{18}$

Through the process of highlighting the latent linguistic attributes of tools for spatial production, our intention was not to infer that gender is wholly shaped by language. Instead, we take the view - as feminist constructivists - that gender is socially constructed and therefore open to negotiation. However, within a society increasingly fraught with hierarchy and inequality, negotiations are not taking place between equal partners ${ }^{19}$ because the tools of production are not universally created or owned. This is where invented or re-imagined tools can play an important role in destabilizing and disrupting the influence of gender hierarchies over designed processes and outcomes, and indeed all hierarchies within the professional field of spatial production. Whereas constructivism identifies that objects act as a form of "glue" that facilitates social interaction, ${ }^{20}$ gendered tools become the objects to which gender is delegated ${ }^{21}$ abstracted and, therefore, easier to name or re-name - whether we use gendered or un-gendered terms to do so. In our view, it is only through doing this that we can become conscious of the latent or explicit biases within our own processes, and work with (1) a critical awareness of the influence of gendered tools over our design processes and outcomes and a desire to mitigate against them; and (2) the conviction that we are both entitled and able to subvert and disrupt stereotypes, and to assess them critically. For this reason, we conclude that the tools of spatial production and not just the spaces themselves are a part of architecture's historical, theoretical and sociological canon. They are as much a part of the making of architecture as buildings and spaces themselves and their subjective power and influence should be better captured, articulated, shared and understood.

Gem Barton is an author and course leader of B.A. (Hons.) Interior Architecture at the University of Brighton. Her specialisms include design education, the humanization and objectification of space and objects, the gray area between reality and representation, and the use of fiction as a means for driving and understanding architecture.

Harriet Harriss (RIBA) leads the Architecture and Interior Design M.Phil./ Ph.D. programs at the Royal College of Art, London. Her teaching, research, 
and writing are largely focused on pioneering new and even "radical" pedagogic models for design education. Her most recent book, A Gendered Profession (eds. Brown, Harriss, Morrow and Soane, RIBA, 2016) examines ways to address lack of diversity - beyond gender binaries - within today's architecture practice and education environments.
484

Gendered, Non-Gendered, Re-Gendered Tools for Spatial Production

Gem Barton and Harriet Harriss

\section{Notes}

1 Roland Barthes, Mythologies [1957], trans. Annette Lavers (New York: Hill \& Wang, 1973), 139.

2 Eve Kosofsky Sedgwick and Adam Frank, Touching Feeling: Affect, Pedagogy, Performativity (Durham, NC: Duke University Press, 2003), 13-14.

3 Daniel Miller, Material Culture and Mass Consumption (Oxford: Basil Blackwell, 1987), 105.

4 Jennifer L. Prewitt-Freilino, T. Andrew Caswell, and Emmi K. Laakso, "The Gendering of Language: A Comparison of Gender Equality in Countries with Gendered, Natural Gender, and Genderless Languages," Sex Roles 66, nos. 3-4 (2012): 268.

5 Lera Boroditsky, Lauren A. Schmidt, and Webb Phillips, "Sex, Syntax, and Semantics," in Language in Mind: Advances in the Study of Language and Cognition, ed. Dedre Gentner and Susan Goldin-Meadow (Cambridge, MA: MIT Press, 2003), 61.

6 Prewitt-Freilino et al., "Gendering of Language."

7 Anne Curzan, Gender Shifts in the History of English (Cambridge: Cambridge University Press, 2003), 91.

8 Source: labarbelabarbe.org (accessed December 6, 2017).

9 Catherine Ingraham, "Missing Objects," in The Sex of Architecture, ed. Diana Agrest (New York: Harry N. Abrams, 2016), 39.

10 Prewitt-Freilino et al., "Gendering of Language."

11 Harriet Harriss, Ruth Morrow, James Brown, and James Soane, A Gendered Profession: The Question of Representation in Placemaking (London: RIBA Publ., 2016).

12 Penny Sparke, As Long as It's Pink: The Sexual Politics of Taste (London: Pandora, 1995).

\section{References}

- Appleby, Joyce Oldham, Lynn Avery Hunt, and Margaret C. Jacob. 1995. Telling the Truth about History. New York: W. W. Norton.
13 Hélène Cixous, The Third Body, trans. Keith Cohen (Evanston, IL: Northwestern University Press, 2010), 132.

14 George Perec, Species of Spaces and Other Pieces (London: Penguin, 1997), 210.

15 Henry Hildebrandt, "The Gaps between Interior Design and Architecture," Design Intelligence 10, no. 3 (March 15, 2004), cited in Julieanna Preston, "A Fossick for Interior Design Pedagogies," in After Taste: Expanded Practice in Interior Design, ed. Kent Kleinman, Joanna MerwoodSalisbury, and Lois Weinthal (New York: Princeton Architectural Press, 2012), 100, https://www.di.net/articles/thegaps-between-interior-design-andarchitecture/ (accessed August 7, 2017).

16 Source:

https://architecturefeminisms.org/ (accessed December 6, 2017).

17 Joyce Oldham Appleby, Lynn Avery Hunt, and Margaret C. Jacob, Telling the Truth about History (New York: W. W. Norton, 1995), 260.

18 Ingraham, "Missing Objects," 39.

19 Anne-Jorunn Berg and Merete Lie, "Feminism and Constructivism: Do Artifacts have Gender?," Science, Technology, and Human Values 20, no. 3 (1995): 342.

20 John Law and Wiebe E. Bijker, "Postscript: Technology, Stability and Social Theory," in Shaping Technology/Building Society: Studies in sociotechnical change, ed. Wiebe E. Bijker and John Law (Cambridge, MA: MIT Press, 1992), 7.

21 Bruno Latour, "Technology is Society Made Durable," Sociological Review 38, no. 1 (1991).
- Barthes, Roland. 1973. Mythologies [1957]. Trans. by Annette Lavers. New York: Hill \& Wang. 
- Anne-Jorunn Berg and Merete Lie. 1995. "Feminism and Constructivism: Do Artifacts Have Gender?" Science, Technology, and Human Values 20, no. 3: 342.

- Boroditsky, Lera, Lauren A. Schmidt, and Webb Phillips. 2003. "Sex, Syntax, and Semantics." In Language in Mind: Advances in the Study of Language and Cognition, edited by Dedre Gentner and Susan GoldinMeadow, 61-80. Cambridge, MA: MIT Press.

- Cixous, Hélène. 2010. The Third Body, translated by Keith Cohen. Evanston, IL: Northwestern University Press.

- Curzan, Anne. 2003. Gender Shifts in the History of English. New York: Cambridge University Press.

- Harriss, Harriet, Ruth Morrow, James Brown, and James Soane. 2016. A Gendered Profession: The Question of Representation in Placemaking. London: RIBA Publ.

- Hildebrandt, Henry. 2012. "The Gaps between Interior Design and Architecture," Design Intelligence 10, no. 3 (March 15, 2004), cited in Julieanna Preston, "A Fossick for Interior Design Pedagogies." In After Taste: Expanded Practice in Interior Design, edited by Kent Kleinman, Joanna MerwoodSalisbury, and Lois Weinthal, 100. New York: Princeton Architectural Press. https://www. di.net/articles/the-gaps-between-interiordesign-and-architecture/ (accessed August 7, 2017).
- Ingraham, Catherine. 2016. "Missing Objects." In The Sex of Architecture, edited by Diana Agrest. New York: Harry N. Abrams.

- Latour, Bruno. 1991. "Technology is Society Made Durable.” Sociological Review 38, no. 1: 103-132.

- Law, John, and Wiebe E. Bijker. 1992. "Postscript: Technology, Stability and Social Theory." In Shaping Technology/Building Society: Studies in Sociotechnical Change, edited by Wiebe E. Bijker and John Law, 290-308. Cambridge, MA: MIT Press.

- Miller, Daniel 1987. Material Culture and Mass Consumption. Oxford: Basil Blackwell.

- Perec, George 1997. Species of Spaces and Other Pieces. London: Penguin.

- Prewitt-Freilino, Jennifer L., T. Andrew Caswell, and Emmi K. Laakso. 2012. "The Gendering of Language: A Comparison of Gender Equality in Countries with Gendered, Natural Gender, and Genderless Languages," Sex Roles 66, nos. 3-4: 268-281.

- Sedgwick, Eve Kosofsky, and Adam Frank. 2003. Touching Feeling: Affect, Pedagogy, Performativity. Durham, NC: Duke University Press.

- Sparke, Penny. 1995. As Long as it's Pink: The Sexual Politics of Taste. London: Pandora.

- Source: https://architecturefeminisms.org/ (accessed December 6, 2017). 